\title{
A Study for Usability Risk Level in Physical User Interface of Mobile Phone
}

\author{
Beomsuk Jin, Sangmin Ko, Jaeseung Mun, and Yong Gu Ji* \\ Yonsei University., 134 Sinchon-Dong, Seodaemun-gu, Seoul, Korea \\ \{kbf2514jin, sangminko, mjs, yongguji\} @yonsei.ac.kr
}

\begin{abstract}
The purpose of this study is to develop a framework of quantitative evaluation of PUI risk level to ensure the usability in designing mobile devices. Three PUI factors-key type, use scene and device form-were selected as the main criteria for PUI risk level. They are defined as Key Manipulation Value (KMV), Function Manipulation Value (FMV) and Handling Value (HV), considering the requirements. In short, this study provides a framework of quantitative evaluation with the requirements of the three PUI factors, and analyzes risk level by KMV, FMV and HV. This result can be utilized as a criterion for usability at the design phase. In addition, evaluation with this framework at the early design phase helps to anticipate the problems, so the opportunity to solve the problem can be offered in advance.
\end{abstract}

Keywords: Mobile Phone, Physical User Interface, Risk Level.

\section{Introduction}

These days, many electronic products are rapidly improved by development of digital and telecommunication technologies. As various functions are added in digital products, product's UI, exterior design, application and usability are affected by these additional changes. Especially, mobile devices are no longer only a device for calling and sending SMS. New functions such as camera, game, DMB, GPS and wireless internet have been established as core components by development of advanced software and hardware technology. This multimedia device has become feasible through digital convergence. Also it became a core-device to satisfy users' various requirements in many fields such as entertainment, business and information [4]. However, as various functions are added into one small device, complexity of the device is causing inefficiency in device control [7]. Therefore UI design that can support user satisfaction and ease of use is getting important.

In general, UI is classified with Graphic User Interface (GUI) and Physical User Interface (PUI). PUI is the term that includes practical and physical characteristics which is related to device's exteriors like buttons, switches and levers to manipulate the device. This must be concerned in early design process and is highly related to context of GUI, which executes applications through display and gives a feedback

\footnotetext{
* Corresponding author.
} 
from its execution [2]. Desktop users devote all of their visual resources to the application which they are interacting. In contrast users of mobile devices, are typically in motion while they are using their device, can not devote their all resources to interact with mobile application. Moreover, the mobile devices are getting smaller and more multi-functional so the form types are expanded from basic form type, bar type, folder type and slide type to advanced and mixed type, swing and swivel type. This change causes difficulties in use due to limited screen real estate and limitation in design of physical buttons [1]. Thus, multi-functional and minimized mobile device has more problems than other digital devices, which leaves an important challenge to overcome the limitation of efficient control for using many functions of devices. Mobile device is a unique type of digital convergence appliance in that PUI and GUI are combined. Therefore, it must be designed with advanced paradigm as preceding ergonomics about hand-tools [6].

In this paper, ease of use is evaluated in the aspect of PUI of calling, SMS, camera, MP3 and DMB using mobile device that is affected by mobile device's physical components(device type, button type and button position). Three PUI evaluation factors are selected: key-type, use-scene, form-factor. Key-type evaluates the degree of efficiency about performing task, use-scene evaluates controllability due to button region and button type, and form-factor evaluates the degree of interruption among key types. The three PUI evaluation values are defined as Key Manipulation Value (KMV), Function Manipulation Value (FMV), Handling Value (HV), respectively. Each of three evaluation values generated mobile device's PUI risk level by estimating requirements related to PUI. Also, the alternatives, which can solve the problem of PUI, are made by analyzing the reasons of high risk level. As a result, mobile device's risk level can be evaluated by three defined PUI evaluation values KMV, FMV and HV. By these, PUI evaluation framework is generated, which can find the predictable problems of ease of use and manage the problems in early design step.

\section{Literature Review}

Previous researches were examined to extract requirements about key-type, use-scene, and form-factor.

In most of previous studies about requirements of Key-type, improving user performance in each task was the main issue. Nielsen studied supporting visual and tactile feedback to improve tool's controllability[5]. Also, the necessity of error prevention which reduces errors occurred from user's mistakes is mentioned. These are main requirements for hand tool device. Shneiderman researched to improve menu navigation for structural and nonstructural information searching by measuring frequency of button usage, accessibility for manipulation, user satisfaction [12]. This research is about most efficient button which can support user in discrete and continuous tasks. And the result can be applied to the navigation button for menu navigation. Furthermore, the Kasper divided difference of multidimensional control and unidimensional control, and different applicable range of various control types related to discrete control or continuous control were analyzed in this paper [9]. 
About interface design of mobile device's keypad, efficient text input and control method were studied, and intuitive and efficient guideline for key arrangement was researched. A new advanced input method was proposed with consideration of balancing input efficiency, ergonomics, usability and cost [11]. Also text input using mobile device is emphasized and a research about comparison and evaluation by calculated input time by Fitt's law was done by Silverberg [13]. Even though it needs little force to manipulate device, user can feel fatigue by finger angle in short time. For that reason, maximum muscular strength which is changed by finger angle during key control with grasping device is also researched [3]. In this research, interface design, which is considered button controllability, accuracy and interference, is required.

Lastly, there were many researches about finger's muscular strength that is related to hand grip and button control design of electronic product in ergonomics' view. This paper focused not only on tool grip design but also on optimizing the best knob shape and size, grip force and grip type using anatomic structure of hand [8]. Miniaturization of mobile device will bring difficulty at the input method. For that reason, Nambu Hirotaka proposed that users need to grip different part of device when using the right bottom part of mobile device [10]. When user tries to input character continuously, the grip-stability with some friction can provide comfort to users; additional research about a bottom part of mobile device's grip is performed.

\section{Risk Level Evaluation Methodology}

Evaluation of mobile device's risk level consists of 4 steps. In the first step, mobile device's features of existing mobile phones are analyzed. The form of device and motion of each form are analyzed as well. Also types of each key and main keys for controlling calling, SMS, camera. MP3 and DMB were investigated. In second step, 3 PUI evaluation factors(key-type, use-scene and form-factor) requirement are collected through previous researches and literature research to estimate the requirement's weight. In third step, the values of KMV, FMV and HV are defined to calculate the risk level quantitatively. Finally, the last step evaluated PUI risk level of mobile device according to evaluation framework of risk level (Fig. 1).

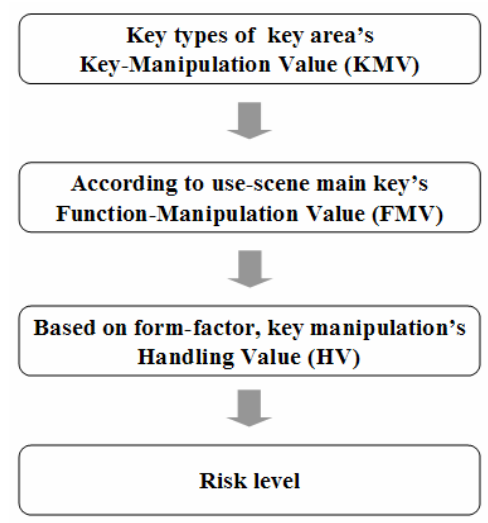

Fig. 1. Framework of PUI risk level 


\subsection{Feature Analysis of Mobile Devices}

Physical movements of different device types are analyzed for evaluating PUI risk level. 133 products (Domestic product: 101, Foreign product: 32) were analyzed. Mobile devices are divided into 4 kinds of form-type(bar, folder, slider and swing). And each different form-types of devices had 13 physical transformations (Table 1). Bar-type consist of normal bar-type and mixed bar-type. Normal bar-type is bar-type without transformation. And mixed bar-types are combined with swing or swivel type. Folder-type consists of normal type (up type) and abnormal type (left-right, upswing and up-swivel type). Slide-type is divided into up, down and up-down type. And there are mixed slide-types which are combined with up type and swing type or swivel type. Normal swing-type is also founded. We defined two positions of mobile devices. The position without transformation is defined as 'base position' and the position with ion is defined as 'home position'.

Table 1. Form of mobile devices

\begin{tabular}{c|l}
\hline Form-type & \multicolumn{1}{c}{ Form-factor(Movement) } \\
\hline \multirow{4}{*}{ Bar } & Bar \\
\cline { 2 - 2 } & Bar + Swing \\
\cline { 2 - 2 } & Bar + Swivel \\
\cline { 2 - 2 } Folder & Up \\
\cline { 2 - 2 } & Right and Left \\
\cline { 2 - 2 } & Up + Swing \\
\cline { 2 - 2 } & $\mathrm{Up}+$ Swivel \\
\hline \multirow{4}{*}{ Slider } & $\mathrm{Up}$ \\
\cline { 2 - 2 } & $\mathrm{Up}+$ Down \\
\cline { 2 - 2 } & Down \\
\cline { 2 - 2 } & $\mathrm{Up}+$ Swing \\
\cline { 2 - 2 } & $\mathrm{Up}+$ Swivel \\
\hline Swing & \\
\hline
\end{tabular}

Mobile device is divided into navigation area, function area, numeric area and side area, and key-type of each area were investigated (Table 2). And dorm key, touch key, jog-disk, jog-stick and wheel are used in each key-area of mobile device.

Table 2. Key-type in each key-area

\begin{tabular}{c|l}
\hline Key-area & \multicolumn{1}{c}{ Key-type } \\
\hline Navigation & Dorm key, Touch key, Jog-disk, Jog-stick, Wheel \\
\hline Function & Dorm key, Touch key, Jog-disk, Jog-stick \\
\hline Numeric & Dorm key, Touch key, Wheel \\
\hline Side & Dorm key, Touch key, Jog-disk, Jog-stick, Wheel \\
\hline
\end{tabular}

Generally in mobile device, there are various functions. However in this research 5 main functions(calling, SMS, camera, MP3 and DMB) which have high usage 
frequency were selected to be evaluated. Also main-key in each key-area was selected to analyze the key-area which is needed to control each functions (Table 3).

Table 3. Main-key and key-area in each function

\begin{tabular}{|c|c|c|}
\hline Function & Main-key & Key-area \\
\hline \multirow{3}{*}{ Calling } & Numeric key & Numeric \\
\hline & Calling, clear, end key & Function \\
\hline & Volume control key & Side \\
\hline \multirow{4}{*}{$\begin{array}{l}\text { Short Message Service } \\
\text { (SMS) }\end{array}$} & Numeric key & Numeric \\
\hline & Mode switch key & Function \\
\hline & Clear, confirmation key & Function \\
\hline & Specific letter key & Navigation \\
\hline \multirow{6}{*}{ Camera } & \multirow{2}{*}{ Shutter key } & Function \\
\hline & & Side \\
\hline & \multirow{2}{*}{ Zoom key } & Navigation \\
\hline & & Side \\
\hline & \multirow{2}{*}{ Brightness control key } & Navigation \\
\hline & & Side \\
\hline \multirow{4}{*}{ MP3 } & Play, Stop key & Function \\
\hline & Music search key & Navigation \\
\hline & \multirow{2}{*}{ Volume control key } & Navigation \\
\hline & & Side \\
\hline \multirow{4}{*}{ DMB } & \multirow{2}{*}{ Channel switch key } & Navigation \\
\hline & & Numeric \\
\hline & \multirow{2}{*}{ Volume control key } & Navigation \\
\hline & & Side \\
\hline
\end{tabular}

As a result of investigation and analysis, classified form-type of mobile device, key-type in each key-area and main-keys in each function were selected as evaluation components.

\subsection{Requirement Collecting and Weight Assessment}

Requirements asked in PUI factors (review, key-type, use-scene and form-factor) are collected through literature review. And by selection process, 16 requirements are selected; 8 of key-type, 6 of use-scene and 2 of form-factor (Table 4).

Requirement's weight of Key-type was estimated by considering main goal and task of each key-area. About use-scene, requirement's weight was estimated by considering key controllability, performance of key control and interference in key control. Also requirement's weight of Form-factor was estimated by considering interference and stability between form of mobile device and motion of key-type.

The weights of each requirement were verified by HCI experts and mobile device designers' discussion. 
Table 4. Requirement and definition

\begin{tabular}{|c|c|c|c|}
\hline $\begin{array}{c}\text { PUI } \\
\text { factors }\end{array}$ & \multicolumn{2}{|c|}{ Requirement } & Definition \\
\hline \multirow{8}{*}{ 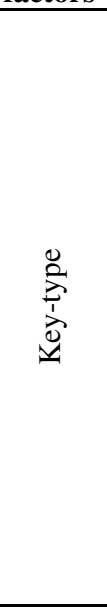 } & \multicolumn{2}{|l|}{ Feedback } & $\begin{array}{l}\text { Provide tactile feedback using control } \\
\text { keys or not }\end{array}$ \\
\hline & \multicolumn{2}{|c|}{ Quick navigation } & $\begin{array}{l}\text { Degree of providing shortcut to } \\
\text { navigate in menu which is consist of } \\
\text { many list }\end{array}$ \\
\hline & \multicolumn{2}{|c|}{ Detail control } & $\begin{array}{l}\text { Degree of providing detail control of } \\
\text { small numeric unit (ex: volume, zoom) }\end{array}$ \\
\hline & \multicolumn{2}{|c|}{ Eye-tracking } & $\begin{array}{l}\text { Degree of providing key manipulating } \\
\text { without eye-tracking }\end{array}$ \\
\hline & \multicolumn{2}{|c|}{ Multidimensional control } & $\begin{array}{l}\text { Degree of providing multidimensional } \\
\text { control in } 2 \text { levels }\end{array}$ \\
\hline & \multicolumn{2}{|l|}{ Error } & $\begin{array}{l}\text { Degree of providing accurate key } \\
\text { manipulation }\end{array}$ \\
\hline & \multicolumn{2}{|c|}{ Thumb range } & $\begin{array}{l}\text { Degree of providing natural key } \\
\text { manipulation in Thumb range }\end{array}$ \\
\hline & \multicolumn{2}{|c|}{ Task performance } & Degree of performing task \\
\hline \multirow{6}{*}{ 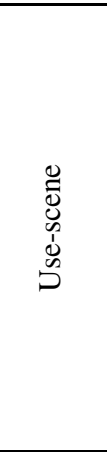 } & \multirow{3}{*}{$\begin{array}{l}\text { Thumb } \\
\text { range } \\
\text { according } \\
\text { to main } \\
\text { used key }\end{array}$} & Stability & $\begin{array}{l}\text { Degree of grip-stability based on key } \\
\text { manipulation and hand position for } \\
\text { using function }\end{array}$ \\
\hline & & Accuracy & $\begin{array}{l}\text { Degree of accuracy of key } \\
\text { manipulation by thumbs' movement }\end{array}$ \\
\hline & & Controllability & $\begin{array}{l}\begin{array}{l}\text { Degree of controllability of key } \\
\text { manipulation for using functions }\end{array} \\
\end{array}$ \\
\hline & \multicolumn{2}{|c|}{ Interference } & $\begin{array}{l}\text { Degree of interference between } \\
\text { manipulated key and other keys }\end{array}$ \\
\hline & \multicolumn{2}{|l|}{ Cognitive } & Degree of cognitive key manipulation \\
\hline & \multicolumn{2}{|c|}{ Performance } & $\begin{array}{l}\text { Degree of performing key manipulation } \\
\text { task }\end{array}$ \\
\hline \multirow{2}{*}{ 章 总 } & \multicolumn{2}{|l|}{ Stability } & $\begin{array}{l}\text { Degree of grip-stability during key } \\
\text { manipulation in each form-factor }\end{array}$ \\
\hline & \multicolumn{2}{|l|}{ Conflict } & 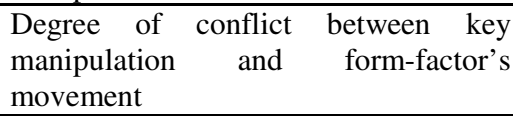 \\
\hline
\end{tabular}

\subsection{Risk Level Definition}

About PUI risk level which can evaluate PUI factors quantitatively was defined. Three values were defined. KMV in key-type is related to controllability and usability for performing task efficiently is defined. FMV of use-scene is related to controllability and usability of key manipulation for using functions. And about Form-factor, HV is related to controllability and usability of those is changed by transformation of mobile device's form. Table 5 shows the value which represents the degree of control efficiency for evaluating PUI risk level. 
Table 5. Control efficiency value

\begin{tabular}{c|l|l}
\hline Value & Requirement & \multicolumn{1}{|c}{ Definition } \\
\hline $\begin{array}{c}\text { KMV Manipulation } \\
\text { Value) }\end{array}$ & Key- type & $\begin{array}{l}\text { Degree of control efficiency of each } \\
\text { key-type during performing task }\end{array}$ \\
\hline $\begin{array}{c}\text { FMV } \\
\begin{array}{c}\text { Function Manipulation } \\
\text { Value) }\end{array}\end{array}$ & $\begin{array}{l}\text { Use-scene } \\
\text { (Function) }\end{array}$ & $\begin{array}{l}\text { Degree of control efficiency of each } \\
\text { key-type during performing } \\
\text { function }\end{array}$ \\
\hline HV & Form-factor & $\begin{array}{l}\text { Degree of control efficiency of each } \\
\text { key-type during performing } \\
\text { function in each position }\end{array}$ \\
\hline
\end{tabular}

\subsection{Risk Level Evaluation}

PUI risk level is evaluated in 3 steps. Figure 2 shows evaluation procedure of PUI risk level. In first step, KMV is generated by evaluation of the degree of requirement's satisfaction in 5 investigated mobile devices' key-types. In second step, FMV is generated by evaluation of the degree of requirement's satisfaction in use-scene using KMV which is generated in first step. Similarly, HV is generated by evaluation of the degree of requirement's satisfaction in each form-factor using FMV. Lastly 1 minus $\mathrm{HV}$ value is risk level of mobile device.

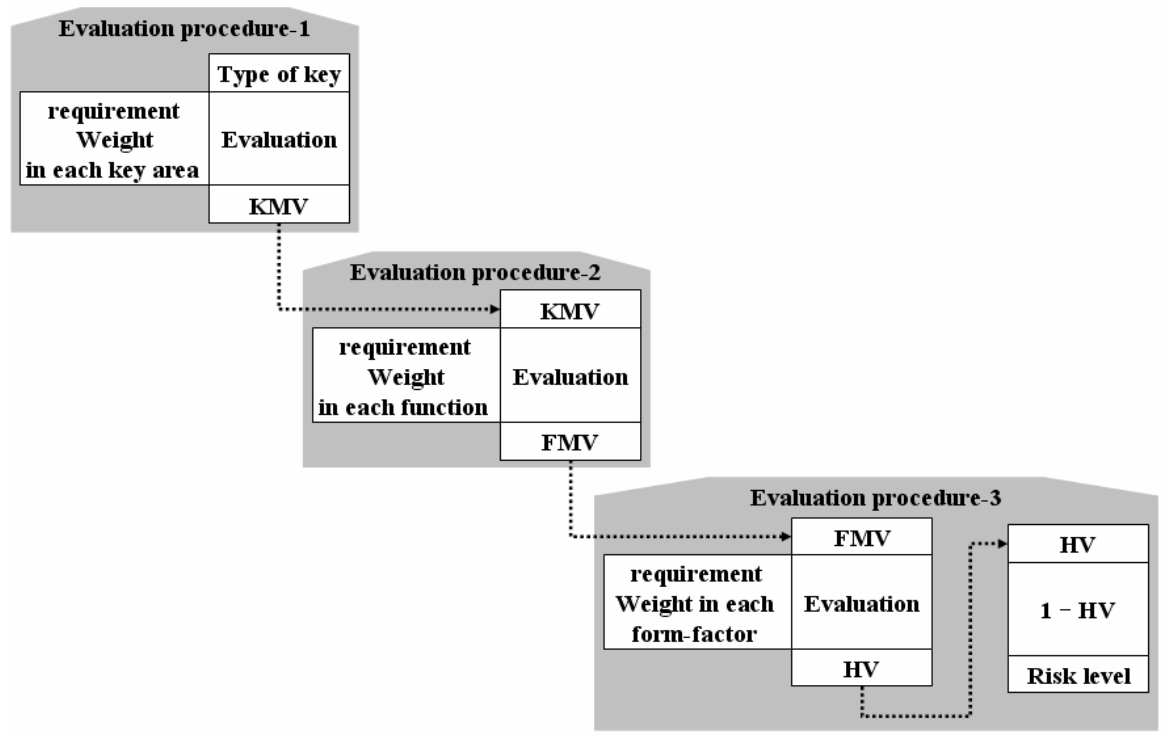

Fig. 2. Evaluation procedure of PUI risk level

Figure 3 shows the method that calculates KMV, FMV, and HV. Using this measurement method, for the last, PUI risk level was calculated. 


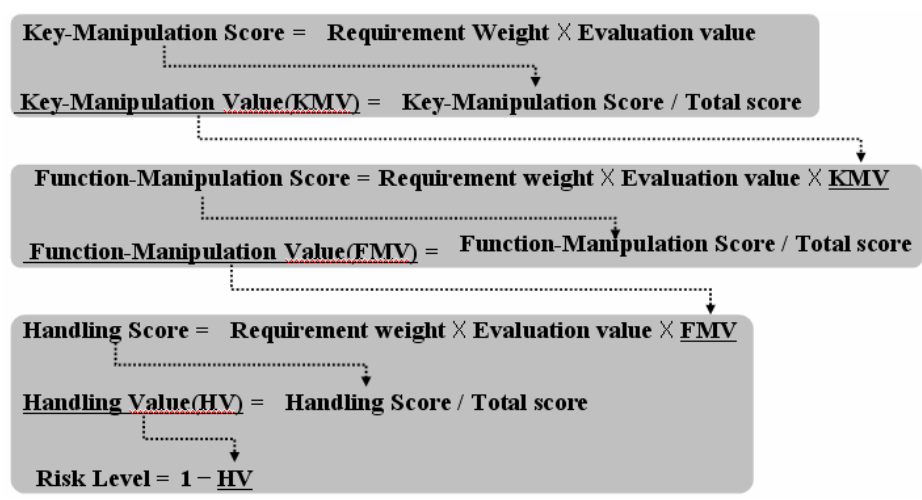

Fig. 3. Measurement method of KMV, FMV, HV

\section{Conclusion and Discussion}

The result of PUI risk level is produced by mobile device evaluation method of this paper. For example, figure 4 shows the results of risk level of 11 bar-type mobile devices.

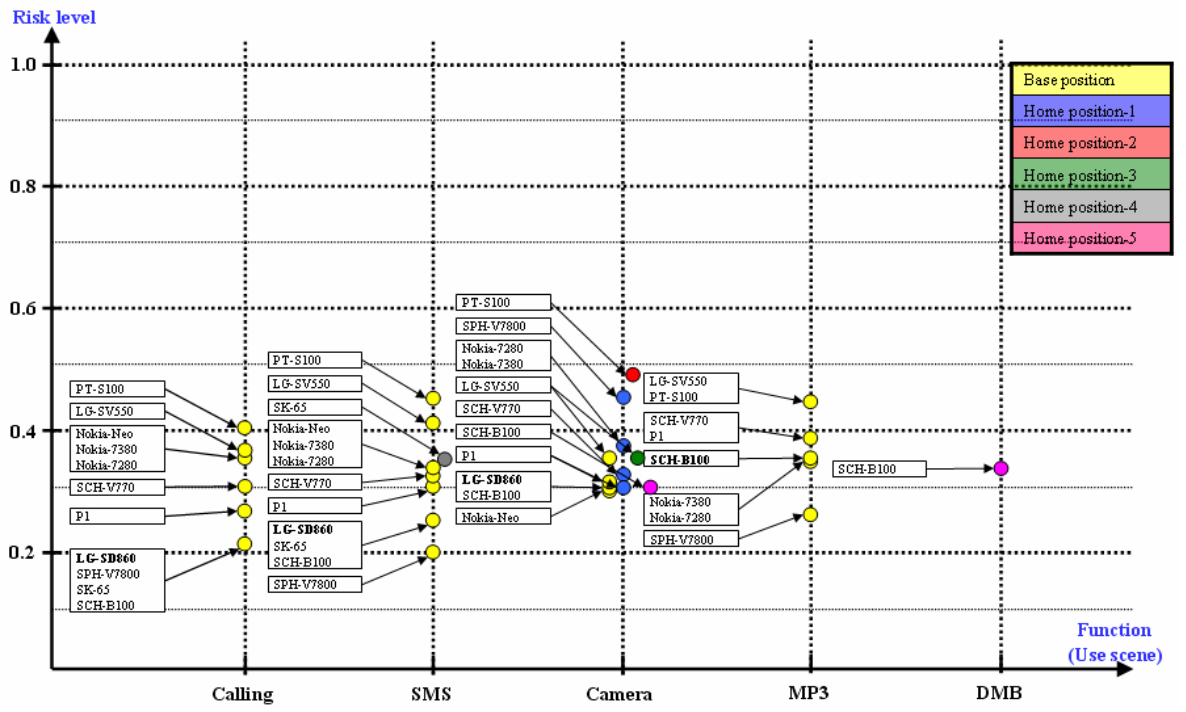

Fig. 4. PUI risk level of bar-type mobile device

In this paper, mobile device's requirements of PUI factors; key-type, use-scene and form-factor are extracted. And we developed risk level evaluation framework for mobile device's PUI design using quantitative value; KMV, FMV and HV. Using this framework, in early design step, designers can evaluate PUI risk level quantitatively. 
In consequence, the framework provides quantitative result based on organized method for mobile device's PUI factors. Also as problems of PUI in early mobile device concept were predictive, designer can get an oppotunity to solve the problems easily. However, we only focused on PUI factors without GUI factors in this research so that the evaluation framework can't deal with whole part of mobile device. Therefore further work that includes menu structure and visual component(GUI factors) is needed.

\section{References}

1. Brewster, S.A.: Overcoming the Lack of Screen Space on Mobile Computers. Personal and Ubiquitous computing 6(3), 188-205 (2002)

2. Swindells, C., MacLean, K.E.: A Case-Study of Affect Measurement Tools for Physical User Interface Design. Graphic Interface, pp. 243-250 (2006)

3. Gilbert, B.C., Hahn, H.A., Gilmore, W.E., Schurman, D.L.: Thumb up:anthropometry of first finger. Human factors 20(6), 747-750 (1988)

4. How to Cope with Diffusion of Mobile Convergence. Samsung Economic Research Institute (2005) http://www.seri.org

5. Nielsen, J.: Usability Engineering. Morgan Kaufmann, San Francisco (1994)

6. Lumsden, J., Brewster, S: A Paradigm Shift:Alternative Interaction Techniques for Use with Mobile \& Wearable Devices (2003)

7. Murphy, J., Kjeldskov, J., Howard, S.: THE CONVERGED APPLIANCE - I LOVE IT...BUT I HATE IT. In: Proceedings of OZCHI 2005, Canberra, Australia (November 2005)

8. Kadefors, R., Areskoug, A., Dahlman, S., Kilbom, A., Sperling, I., Oester, J.: An approach ergonomics evaluation of the hand tools. Applied Ergonomics 24(3), 203-211 (1993)

9. Hornbaek, K.: Current practice in measuring usability-Challenges to usability studies and research. Human Computer Studies 64, 79-102 (2005)

10. Hirotaka, N.: Reassessing Current Cell Phone Designs-Using Thumb Input Effectively. CHI 2003, New Horizons (2003)

11. Ha, R.W., Ho, P.-H., Shen, X.S.: SIMKEYS-An Efficient Keypad Configuration for Mobile Communications. IEEE Communications Magazine, University of Waterloo, (November 2004)

12. Shneiderman, B.: Designing the User Interface Strategies for Effective Human Computer Interractive Working. Addison-wesley, Reading (1987)

13. Silfverberg, M., Mackenzie, I.S., Korhonen, P.: Predicting text entry speed mobile phone. CHI2000 Letters 2(1), 9-16 (2000) 